\title{
Effects of occasional reinforced trials during extinction on the reacquisition of conditioned responses to food cues
}

Citation for published version (APA):

van den Akker, K., Havermans, R. C., \& Jansen, A. (2015). Effects of occasional reinforced trials during extinction on the reacquisition of conditioned responses to food cues. Journal of Behavior Therapy and Experimental Psychiatry, 48, 50-58. https://doi.org/10.1016/j.jbtep.2015.02.001

Document status and date:

Published: 01/09/2015

DOI:

10.1016/j.jbtep.2015.02.001

Document Version:

Publisher's PDF, also known as Version of record

Document license:

Taverne

Please check the document version of this publication:

- A submitted manuscript is the version of the article upon submission and before peer-review. There can be important differences between the submitted version and the official published version of record.

People interested in the research are advised to contact the author for the final version of the publication, or visit the DOI to the publisher's website.

- The final author version and the galley proof are versions of the publication after peer review.

- The final published version features the final layout of the paper including the volume, issue and page numbers.

Link to publication

\footnotetext{
General rights rights.

- You may freely distribute the URL identifying the publication in the public portal. please follow below link for the End User Agreement:

www.umlib.nl/taverne-license

Take down policy

If you believe that this document breaches copyright please contact us at:

repository@maastrichtuniversity.nl

providing details and we will investigate your claim.
}

Copyright and moral rights for the publications made accessible in the public portal are retained by the authors and/or other copyright owners and it is a condition of accessing publications that users recognise and abide by the legal requirements associated with these

- Users may download and print one copy of any publication from the public portal for the purpose of private study or research.

- You may not further distribute the material or use it for any profit-making activity or commercial gain

If the publication is distributed under the terms of Article $25 \mathrm{fa}$ of the Dutch Copyright Act, indicated by the "Taverne" license above, 


\title{
Effects of occasional reinforced trials during extinction on the reacquisition of conditioned responses to food cues
}

\author{
Karolien van den Akker*, Remco C. Havermans, Anita Jansen \\ Faculty of Psychology and Neuroscience, Department of Clinical Psychological Science, Maastricht University, P.0. Box 616, 6200 MD Maastricht,
} The Netherlands

\section{A R T I C L E I N F O}

\section{Article history:}

Received 8 September 2014

Received in revised form

2 February 2015

Accepted 4 February 2015

Available online 13 February 2015

\section{Keywords:}

Appetitive conditioning

Occasional reinforcement

Extinction

Reacquisition

Impulsivity

Dieting success

\begin{abstract}
A B S T R A C T
Background and objectives: Successful long-term dieting appears to be difficult, and part of its difficulty might be explained by processes related to classical appetitive conditioning. Increasing the speed of extinction of appetitive responses to food cues and decreasing the magnitude of returns of these responses could help increase the long-term effectiveness of weight loss attempts. Two extinction techniques hypothesized to slow down rapid reacquisition of conditioned appetitive responses were investigated: the provision of 1 ) occasional reinforced extinction trials (OR) and 2) unpaired unconditioned stimuli (USs) during extinction (UNP).

Methods: After acquisition, participants $(\mathrm{N}=90)$ received one of three extinction trainings: OR, UNP, or normal extinction (control), followed by a reacquisition phase. Their desire to eat, US expectancy, and salivation were measured. Effects of impulsivity on different phases of appetitive conditioning were also assessed.

Results: It was found that both extinction techniques were successful in reducing the rate of reacquisition of US expectancies. Participants in the OR condition also demonstrated a slower extinction of US expectancies and desires to eat. However, the reacquisition of conditioned desires was not affected by either extinction technique. Impulsivity did not moderate responses during acquisition or extinction, but appeared to slow down the reacquisition of conditioned desires.

Limitations: US expectancies and eating desires were not completely extinguished, and a few differences in baseline responses caused difficulty in interpreting some of the findings.

Conclusions: It is concluded that the provision of occasional reinforced extinction trials and unpaired USs seem promising techniques to slow down reacquisition, but that additional studies are needed.
\end{abstract}

(C) 2015 Elsevier Ltd. All rights reserved.

\section{Introduction}

Over the past decades, the prevalence of overweight and obesity has been continually increasing. Around $70 \%$ of the US population is currently overweight, of which half qualifies for obesity (Ogden, Carroll, Kit, \& Flegal, 2012). Attempts to lose the excess weight are common: approximately $40 \%$ of all US adults have engaged in weight loss practices in the previous year (Weiss, Galuska, Khan, \& Serdula, 2006). However, successful long-term weight loss appears difficult. Only one in five dieters is able to lose at least $10 \%$ of their

\footnotetext{
* Corresponding author. Tel.: +31 (0) 4338 81981; fax: +31 (0) 433884196.

E-mail address: karolien.vandenakker@maastrichtuniversity.nl (K. van den Akker).
}

initial weight and maintain the loss for at least one year (Wing \& Phelan, 2005).

Conditioning models propose roles for learning processes in explaining the difficulty to chronically adhere to restrictive diets. In response to an (initially neutral) stimulus (conditioned stimulus, $\mathrm{CS}$ ) that has become associated with eating palatable food (unconditioned stimulus, US), cue reactivity is elicited (Jansen, 1998). Any stimulus could become associated with food intake, such as the sight or smell of food, emotions, or environments (Jansen, 1998; Van den Akker, Jansen, Frentz, \& Havermans, 2013). Cue reactivity includes preparatory responses of the body and a subjective experience of craving, urge or desire to eat (Jansen, 1998; Power \& Schulkin, 2008), and higher levels of cue reactivity are thought to be associated with an increased difficulty to abstain from eating (Jansen, 1998; Jansen, Havermans, \& Nederkoorn, 2011). Therefore, chances to successfully lose weight might be increased by 
diminishing reactivity - for instance, through extinction. During extinction, one is repeatedly exposed to a food cue (CS) without eating (US) to learn that the CS no longer predicts the US. Consequently, cue reactivity should diminish (Jansen et al., 2011). Extinction of cue reactivity is essentially practiced when being on a restrictive diet: a person attempts not to reinforce certain food cues to which he is exposed. However, extinction may take a while, and as long as a CS promotes a relatively high degree of cue reactivity (e.g., desires to eat), dieting efforts are easily undermined. Indirect support for the idea that cue reactivity and dieting success are related stems from a study showing formerly obese successful dieters to be less cue reactive than their unsuccessful counterparts (Jansen, Stegerman, Roefs, Nederkoorn, \& Havermans, 2010), suggesting that their food cue reactivity was successfully reduced (presumably extinguished). Additionally, food cue exposure therapy (during which an individual is repeatedly presented with "forbidden" foods without eating) seems to be effective in decreasing eating in the absence of hunger in obese children (Boutelle et al., 2011), and in reducing the desire to eat and the number of binges in binge eaters (Jansen, Broekmate, \& Heymans, 1992). Thus, to maintain weight loss in the long run it might be necessary to extinguish cue reactivity to certain food cues (CSs).

It is known that extinction results in inhibitory learning that is highly dependent on context, rather than erasure of the CS-US relationship (Bouton, 2002). This is why conditioned appetitive responses can suddenly re-emerge after extinction, promoting "relapse" and limiting the effectiveness of extinction treatments (e.g., Havermans \& Jansen, 2003). There are several conditioning phenomena that can explain such returns of conditioned responses, one of which being rapid reacquisition (for an overview see Bouton, 2011). Rapid reacquisition is characterized by a quick return of responding when a CS is again paired with the US after extinction, and it presumably occurs because of contextual similarities to the original acquisition context (Bouton, 2011). Translated to dieting, rapid reacquisition could cause a "lapse" in the diet (i.e., a rereinforced CS after extinction) to trigger a quick return of appetitive responding to a food cue (Bouton, 2011). This quick return of food cue reactivity after a period of successfully abstaining from eating tasty high-calorie foods could easily end up in a full-blown return of appetitive responses, resulting in a failure to maintain dietary restriction and weight loss.

This classical conditioning interpretation of unsuccessful dieting predicts that dieters can benefit from interventions that reduce or prevent the return of appetitive responses caused by, for instance, rapid reacquisition. While rodent studies, human fear conditioning studies, and a few human appetitive conditioning studies have identified an array of potentially effective techniques (Bouton, 2002; Craske, Treanor, Conway, Zbozinek, \& Vervliet, 2014; Laborda, McConnell, \& Miller, 2011; MacKillop \& Lisman, 2008; Van Gucht, Baeyens, Hermans, \& Beckers, 2013; Van Gucht, Baeyens, Vansteenwegen, Hermans, \& Beckers, 2010), no studies have examined ways of tackling rapid reacquisition of appetitive responses in humans. In rats, one procedure that has been shown to be very effective in slowing down the reacquisition of appetitive responses after extinction is the presentation of some CS-US pairings during extinction (Bouton, Woods, \& Pineño, 2004). During this procedure, after acquisition, a food cue (CS) is occasionally followed by the intake of food (US) during extinction. In a subsequent reacquisition phase, renewed CS-US pairings elicit less responding compared with rats that received a regular extinction training (never a US after the CSs), i.e. the reacquisition of appetitive responses was less rapid. It has been suggested that occasional reinforced trials during extinction enable reinforced trials to be associated with extinction trials, leading to a greater generalization between the extinction and reacquisition context and a slowing down of reacquisition (see Bouton et al., 2004; Woods \& Bouton, 2007). If humans can similarly associate one reinforced CS-US pairing (e.g., eating chocolate once in response to a CS) with no subsequent reinforcements (not eating chocolate during subsequent CS presentations), the effectiveness of extinction training on the long-term could be increased by preventing a full-blown relapse. An eating binge could be prevented using occasional reinforcements as well, by learning to associate consuming one small snack (the CS) with no further (over)eating (US) (Bouton et al., 2004).

Another technique that remarkably slows down reacquisition in rats also involves occasional US presentations during extinction, but in this technique the US is not presented in contingency with its CS; rather, it is not paired with a cue. Unpaired USs during extinction may slow down reacquisition through a mechanism similar to the one described for occasional reinforced extinction: a US may come to signal upcoming extinction trials, slowing down reacquisition (Bouton et al., 2004; Woods \& Bouton, 2007; see also Rauhut, Thomas, \& Ayres, 2001; Vervliet, Vansteenwegen, \& Hermans, 2010). Thus, while animal studies show that extinction procedures that include occasional reinforcements and unpaired US presentations reduce reacquisition of appetitive responses, these techniques have yet to be studied in humans.

Some individuals may be predisposed to reacting stronger to food cues and/or reacting differently to the learning and extinction of appetitive responses. Having an impulsive personality has been related to increased food cue reactivity, overeating, obesity, and reduced dieting success (Guerrieri, Nederkoorn, \& Jansen, 2008; Nederkoorn, Braet, Van Eijs, Tanghe, \& Jansen, 2006; Nederkoorn, Jansen, Mulkens, \& Jansen, 2007; Tetley, Brunstrom, \& Griffiths, 2010). Additionally, some evidence was found for impulsivity to be related to slower extinction of food reward expectations, and to potential differences in acquisition and reacquisition rates (Van den Akker, Jansen, Havermans, \& Bouton, 2014; but see Papachristou, Nederkoorn, Beunen, \& Jansen, 2013). Several authors have proposed mechanisms that may underlie a possible influence of impulsivity during different stages of appetitive conditioning (Corr, 2001, 2002; Corr, Pickering, \& Gray, 1995; Dawe, Gullo, \& Loxton, 2004; Franken, van Strien, Nijs, \& Muris, 2008; Gorenstein \& Newman, 1980; Patterson \& Newman, 1993; Zinbarg \& Mohlman, 1998). For instance, impulsivity may be associated with greater changes in emotional states and increased arousal in appetitive situations, which could strengthen conditioning (Corr, 2001). Increased rash impulsiveness (as measured by the BIS-11) may be related to extinction deficits through worse functioning of the orbitofrontal cortex, which is involved in learning under conditions of changing reward contingencies (see Dawe et al., 2004; McDannald, Jones, Takahashi, \& Schoenbaum, 2014). Based on these models and on previous findings, it may be expected that impulsivity facilitates the acquisition and slows down the extinction of appetitive responses.

In the present study, a differential conditioning paradigm was used in which two different (initially non-food related) boxes served as CSs. During an acquisition phase, one box (the CS+) was repeatedly paired with consumption of chocolate mousse (US), while another box (the CS-) served as within-subject control and was never paired with consumption. Consequently, the CS+ should elicit heightened expectancies to receive the US and an increased desire to eat, compared with the $\mathrm{CS}-$. After acquisition, participants received one of three extinction trainings. Effects of occasional reinforced extinction and unpaired US presentations during extinction on the speed of extinction and reacquisition of appetitive responses to a food CS were examined. It was hypothesized that both techniques would slow down reacquisition relative to a normal extinction procedure, and that occasional reinforcements 
would slow down extinction. The second aim was to examine whether impulsivity is associated with a facilitated acquisition and slowed extinction of conditioned appetitive responses.

\section{Methods and materials}

\subsection{Participants}

Ninety participants took part in the study, of which five participants were replaced by additional participants (two were not aware of the CS-US contingency, and the data of three others was not usable due to technical issues). All participants were undergraduate female students who had indicated to like chocolate prior to participation. To reduce baseline differences in hunger participants were instructed to have a small meal $2 \mathrm{~h}$ prior to participation and to refrain from calorie intake thereafter. Participants were told the study's aim was to investigate the memory of taste. Participants received either $€ 7.50$ or course credit for participation. The study was approved by the local ethical committee.

\subsection{Measurements}

Desire and US expectancy: $100 \mathrm{~mm}$-Visual Analogue Scales (VAS) were used to assess expectancy to receive chocolate mousse ('How strong do you expect this box to contain chocolate mousse at this moment?') and subjective desire for chocolate mousse ('When looking at this box, how strong is your desire for chocolate mousse at this moment?') (in this order). Ratings ranged from 0 (certainly expect this box not to contain chocolate mousse/no desire at all) to 100 (certainly expect this box to contain chocolate mousse/very strong desire).

Salivation: Salivation was measured using dental rolls (Hartmann, $\mathrm{nr} 2,10 \times 35 \mathrm{~mm}$ ) which the participant was instructed to place and remove herself. Two dental rolls were placed between the cheek and lower gum on the left and right side. They were removed after precisely $1 \mathrm{~min}$. The dental rolls were kept in a sealed plastic bag and their weight was registered before and after the saliva was collected, using a weighing scale accurate to $.01 \mathrm{~g}$ (Mettler Toledo, PB3002).

CS preference: After having completed the conditioning phases, participants indicated their CS preference (CS+ or $\mathrm{CS}-$ ) ('If you were allowed to take one of the boxes home, which one would you pick?').

Hunger: To control for hunger, participants filled in a VAS ('How hungry are you at this moment?') ranging from 0 (not hungry at all) to 100 (extremely hungry) before and after the conditioning procedure.

Chocolate mousse liking: To control for differences in the liking of chocolate mousse, participants filled in a VAS ('How much did you like the chocolate mousse?') ranging from 0 (not at all) to 100 (extremely).

Barrett Impulsivity Scale-11 (BIS-11; Patton, Stanford, \& Barratt, 1995): The BIS-11 was used to measure impulsivity. The BIS-11 is a self-report questionnaire and consists of 30 items. Each statement can be rated on a 4-point scale, ranging from rarely/never to always/ almost always. Total scores were calculated, a higher score indicating higher impulsiveness. The BIS-11 has good internal consistency and is well-validated (Patton et al., 1995; Stanford et al., 2009).

Revised Restraint Scale (RS; Polivy, Herman, \& Howard, 1988): To control for differences in dietary restraint (i.e. the intention to restrict food intake) the 10 -item RS was used. Scores range from 0 to 35 , a higher score indicating increased intentions to restrain intake. In student samples, the RS has high internal consistency and good test-retest reliability (Gorman \& Allison, 1995).

All questionnaires were administered in Dutch.

\subsection{Stimuli}

US: A heaped teaspoon of chocolate mousse (approximately $3.5 \mathrm{~g}$, Almhof) served on a teaspoon in a small cup served as US.

CS: Two children's jewelry boxes served as CSs, and contained the US in case of a CS + trial. One box depicted elephants ('Elmer the Patchwork Elephant') and had colored squares and yellow linings, and the other depicted fish ('The Rainbow Fish') and was blue. ${ }^{1}$ Each box functioned as CS+ or CS - for half of the participants within each condition.

\subsection{Design and procedure}

Participants were seen individually between 11 AM and 6 PM. They gave written consent after arrival in the laboratory, filled in a hunger VAS, and baseline salivation was assessed. After that, the participants were shown the jewelry boxes and participants were explicitly instructed that one of these boxes sometimes contained something they would eat, whereas the other box would never contain anything.

All participants then went through three consecutive learning phases: acquisition, extinction, and reacquisition. Participants were randomly assigned to one of three conditions, which differed only in extinction training: normal extinction (control), occasional reinforced extinction trials (OR), or unpaired USs during extinction (UNP).

Acquisition: During acquisition training, all participants received five $\mathrm{CS}+$ and five $\mathrm{CS}$ - trials (trials are described later).

Extinction: Participants then received one of three extinction trainings. All participants were presented with twenty CSO (i.e., the $\mathrm{CS}+$ without the US) trials and twenty CS - trials. Participants in the OR condition received two $\mathrm{CS}+$ trials in addition to the twenty CSO trials (not included in the main analyses and figures). These two reinforced $\mathrm{CS}+$ trials were given relatively early during extinction (on trials 2 and 6) to provide sufficient subsequent trials for extinction to take place. Participants in the UNP condition received two additional US-only trials during the ITIs following trials 2 and 6 (i.e., participants received a small cup containing a teaspoon with chocolate mousse). Each participant in the UNP condition received one unpaired US after a CSO trial and the other after a CS - trial, to ensure complete uncoupling from the $\mathrm{CS}+$ in all participants. Half of the participants in this condition received the CSO unpaired trial first (on trial 2) and the CS- unpaired trial second (on trial 6); for the other half the order was reversed. The control condition did not receive USs during extinction.

Reacquisition: After extinction, all participants received four CS+ and four CS- trials.

After reacquisition, salivation was assessed on one additional CS + and CS - trial. Half of the participants within each condition received the $\mathrm{CS}+$ salivation trial first, and the other half received the $\mathrm{CS}$ - salivation trial first.

The instructions given during the three phases were prerecorded. A trial started when a closed box (CS+ or $\mathrm{CS}_{-}$) was placed in front of the participant, and she was instructed to look at it. After $10 \mathrm{~s}$, expectancy and desire VAS were filled in, and the participant opened the box. In case of a CS + trial, the US inside the box was consumed. In case of a CS- trial the empty box was closed again. The box was then removed from sight, and an inter-trial interval (ITI) of $10 \mathrm{~s}$ started, after which the next trial began. During salivation trials, dental rolls were inserted after expectancy and desire VAS were filled in, but before the boxes were opened and any

\footnotetext{
1 The characters depicted on the boxes are based on children's books.
} 
chocolate mousse was consumed. Thus, a trial was halted during salivation measurements.

The order of presentation of the trials throughout all phases was randomized, with the restriction that no more than two consecutive trial types were the same. Further, half of the participants within each condition received the $\mathrm{CS}_{+}$and the other half the CS - on the first extinction or reacquisition trial, because nonreinforced trials after acquisition and reinforced trials after extinction may alter responding on the following trial.

After the acquisition, extinction, and reacquisition phases were completed, participants filled in questionnaires on their idea about the study's hypothesis, CS preference, hunger, BIS-11, RS, liking of the chocolate mousse and time of pre-experimental food intake.

\subsection{Data reduction and statistical analyses}

The twenty extinction trials were averaged into five extinction blocks. Differential acquisition, extinction, and reacquisition of the desire to eat and US expectancy over time and across conditions were analyzed by using a repeated-measures ANCOVA for each phase of the experiment (acquisition, extinction, and reacquisition) This resulted in 3 (Condition: Control vs. OR vs. UNP) $\times 2$ (CS-type: CS + vs. CS - ) $\times 5 / 5 / 4$ (Acquisition Trial/Extinction Block/Reacquisition Trial) repeated-measures ANCOVAs, including CS-type (CS) and trial (T)/block (B) as within-subjects factors and condition $(\mathrm{C})$ as between-subjects factor. Thus, differential responses were analyzed; i.e. responses to the $\mathrm{CS}+$ were always compared with responses to the $\mathrm{CS}-$. The total score of the BIS-11 was centered and included as covariate in the ANCOVAs to assess effects of impulsivity (I). When appropriate, additional analyses were performed to explore significant interactions.

Conditioned salivary responses were analyzed using a repeatedmeasures ANCOVA, with measurement type (baseline, $\mathrm{CS}+, \mathrm{CS}-$ ) as within-subjects variable, condition as between-subjects factor, and the centered score of the BIS-11 as covariate. CS preference (CS+ or CS-) was analyzed using a binomial test, and chi-square tests were conducted to test for differences in CS preference across conditions. Greenhouse-Geisser epsilon corrections are reported for all repeated-measures analyses whenever sphericity was violated.

\section{Results}

\subsection{Participant characteristics}

The participant characteristics did not differ across conditions (see Table 1).

\subsection{US expectancy}

Participants learned to expect chocolate mousse when presented with the $\mathrm{CS}+$ : a differential acquisition of US expectancies

\section{Table 1}

Participants characteristics per condition; means with standard deviations in parentheses.

\begin{tabular}{llllrl}
\hline & Control & OR & UNP & $F(2,87)$ & $p$ \\
\hline $\mathrm{n}$ & 30 & \multicolumn{1}{l}{30} & \multicolumn{1}{l}{30} & & \\
Age & $19.20(1.37)$ & $20.50(6.25)$ & $19.77(1.73)$ & .87 & .42 \\
BMI & $22.08(2.83)$ & $23.06(2.79)$ & $21.55(3.84)$ & 1.72 & .18 \\
Baseline hunger $^{\mathrm{a}}$ & $53.60(18.23)$ & $51.17(22.91)$ & $49.33(24.30)$ & .29 & .75 \\
Post hunger $^{\mathrm{a}}$ & $43.83(25.54)$ & $41.50(20.47)$ & $50.67(28.92)$ & 1.10 & .34 \\
BIS-11 total & $58.87(8.73)$ & $57.33(8.30)$ & $59.37(8.73)$ & .46 & .64 \\
RS & $10.27(5.06)$ & $12.83(5.48)$ & $11.40(3.45)$ & 2.20 & .12 \\
Liking mousse & $77.87(17.35)$ & $77.33(23.19)$ & $79.73(16.12)$ & .13 & .88 \\
\hline
\end{tabular}

\footnotetext{
${ }^{a}$ Hunger ratings changed significantly over time, $F(1,87)=5.08, p=.03, \eta_{\mathrm{p}}^{2}=.06$, and this change did not differ across conditions, $F(2,87)=1.89, p=.16$
}

was present $(C S \times T), F(3.01,252.71)=77.53, p<.001, \eta_{p}^{2}=.48($ see Fig. 1). Differential expectancy did not differ across conditions or levels of impulsivity $(\mathrm{CS} \times \mathrm{T} \times \mathrm{C} / \mathrm{I})$, nor by their interaction $(\mathrm{CS} \times \mathrm{T} \times \mathrm{C} \times \mathrm{I}), F s<1$. A significant differentiation was present on trial $5, F(1,84)=930.36, p<.001, \eta_{\mathrm{p}}^{2}=.92$, with no differences across conditions, $F<1$.

On the first extinction block, conditions differed in differential US expectancies, $F(2,84)=4.57, p=.01, \eta_{\mathrm{p}}^{2}=.10$ : the differentiation was already larger for the OR condition vs. the control condition, $F(1,56)=9.48, p=.003, \eta_{\mathrm{p}}^{2}=.15$, while there was no significant difference in differentiation for the UNP vs. OR condition, $F(1$, $56)=1.72, p=.20, \eta_{\mathrm{p}}^{2}=.03$, and UNP vs. control condition, $F(1$, $56)=2.71, p=.11, \eta_{\mathrm{p}}^{2}=.05$. The significant difference across conditions on extinction block 1 was due to the manipulations, since the conditions did not differ in differential US expectancy ratings on the first two extinction trials (before any USs were provided, hence including the additional CS-US trial in OR), $F s<1$. US expectancies extinguished $(\mathrm{CS} \times \mathrm{B}), F(2.52,212.65)=126.73, p<.001, \eta_{\mathrm{p}}^{2}=.60$, with differences across conditions (CS $\times \mathrm{B} \times \mathrm{C}), \quad F(5.06$, $212.65)=8.95, p<.001, \eta_{\mathrm{p}}^{2}=.18$ (see Fig. 1 ). Next, extinction was compared for each pair of conditions. As expected, the OR condition showed a significantly slower extinction performance compared with both the control and UNP conditions, $F(2.72,152.02)=14.30$, $p<.001, \eta_{\mathrm{p}}^{2}=.20 ; F(2.72,151.76)=11.72, p<.001, \eta_{\mathrm{p}}^{2}=.17$ (control vs. UNP: $F=1.17, n s$ ). On the last extinction block, a differentiation between $\mathrm{CS}+$ and $\mathrm{CS}-$ expectancy scores was still present, $F(1$, $84)=37.41, p<.001, \eta_{\mathrm{p}}^{2}=.31$, that differed across conditions, $F(2$, $84)=4.51, p=.01, \eta_{\mathrm{p}}^{2}=.10$ : differential expectancies in the OR vs. control condition were still significantly larger, $F(1,56)=7.58$ $p=.008, \eta_{\mathrm{p}}^{2}=.12$, and non-significantly larger than those in the UNP condition, $F(1,56)=3.21, p=.08, \eta_{\mathrm{p}}^{2}=.05$ (control vs. UNP: $F=1.45, n s)$. This pattern of results shows that occasional reinforcements during extinction (but not unpaired USs) slow down extinction performance. Impulsivity did not moderate extinction $(\mathrm{CS} \times \mathrm{B} \times \mathrm{I} ; \mathrm{CS} \times \mathrm{B} \times \mathrm{C} \times \mathrm{I}), F=1.71, n s, F<1$.

On reacquisition trial 1 , the differentiation between $\mathrm{CS}+$ and CS - expectancy scores was still present, $F(1,84)=15.46, p<.001$, $\eta_{\mathrm{p}}^{2}=.16$, with marginally significant differences across conditions, $F(2,84)=2.71, p=.07, \eta_{\mathrm{p}}^{2}=.06$ : the control condition did not differ from the OR and UNP conditions, $F(1,56)=2.75, p=.10, F<1$, while the differentiation was larger for the OR vs. UNP condition, $F(1$, $56)=4.79, p=.03, \eta_{\mathrm{p}}^{2}=.08$. Reacquisition of US expectancies was significant $(\mathrm{CS} \times \mathrm{T}), F(2.37,198.94)=140.68, p<.001, \eta_{\mathrm{p}}^{2}=.63$, and differed across conditions (CS $\times \mathrm{T} \times \mathrm{C}), F(4.74,198.94)=4.29$, $p=.001, \eta_{\mathrm{p}}^{2}=.09$ (see Fig. 1). In line with our hypotheses, both occasional reinforced trials during extinction, $F(2.04$, $114.42)=6.75, p=.002, \eta_{\mathrm{p}}^{2}=.11$, and unpaired USs, $F(2.44$, $136.41)=3.73, p=.02, \eta_{\mathrm{p}}^{2}=.11$, slowed down reacquisition relative to normal extinction. Furthermore, reacquisition differed between the OR and UNP conditions, $F(2.49,139.25)=2.83, p=.05, \eta_{\mathrm{p}}^{2}=.05$. This could indicate occasional reinforced trials during extinction to be more effective in reducing the speed of reacquisition than unpaired USs during extinction, although the drawing of any conclusions regarding differences in reacquisition patterns between the OR vs. UNP conditions is complicated by the fact that expectancies differed on reacquisition trial 1 . Impulsivity did not moderate reacquisition ( $\mathrm{CS} \times \mathrm{T} \times \mathrm{I}$; $\mathrm{CS} \times \mathrm{T} \times \mathrm{C} \times \mathrm{I}$ ) $, F=2.28, n s, F<1$. Thus, as expected, provision of unpaired USs and, possibly even more so, occasional reinforced trials during extinction reduced the speed of reacquisition of US expectancies.

\subsection{Desire to eat}

Participants developed a conditioned desire to eat, as shown by a significant CS $\times \mathrm{T}$ interaction, $F(2.93,246.33)=14.98, p<.001$, 


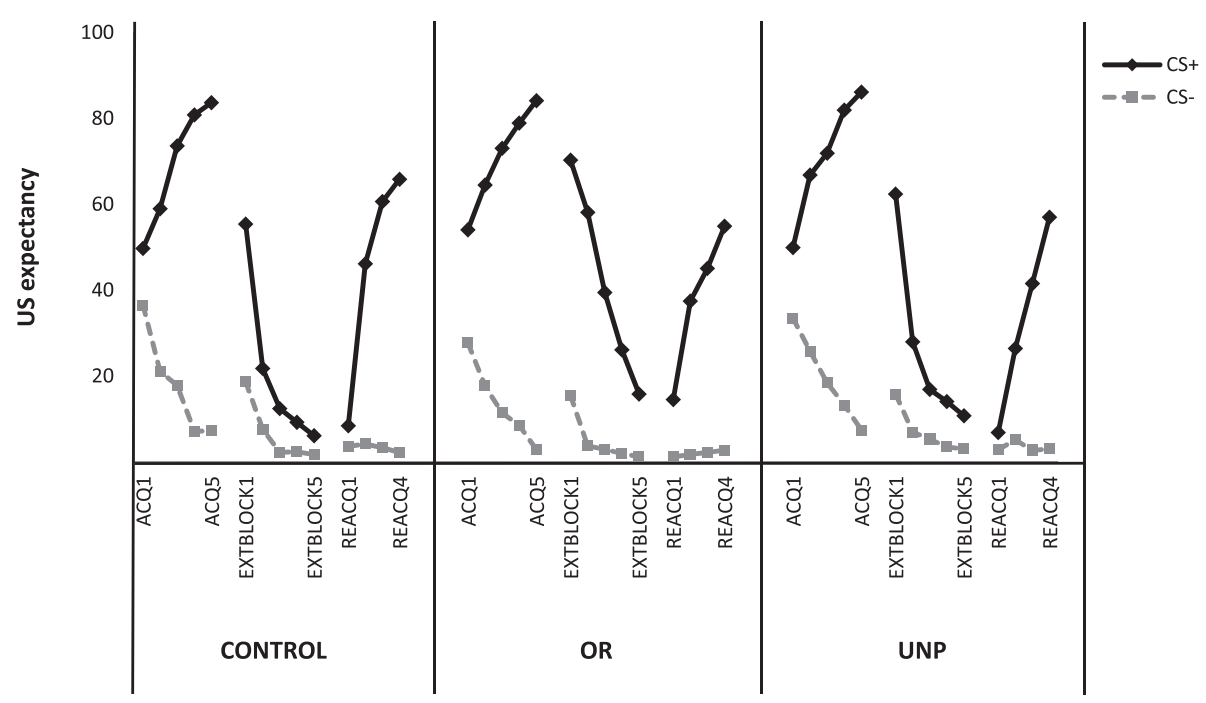

Fig. 1. Mean US expectancy by CS-type, trial or block, condition, and phase of the experiment.

$\eta_{\mathrm{p}}^{2}=.15$, this acquisition being similar across conditions $(\mathrm{CS} \times \mathrm{T} \times \mathrm{C}), F<1$ (see Fig. 2). Impulsivity did not moderate these interactions $(\mathrm{CS} \times \mathrm{T} \times \mathrm{I}$; $\mathrm{CS} \times \mathrm{T} \times \mathrm{C} \times \mathrm{I}), \mathrm{Fs}<1$. A significantly larger desire in response to the CS + compared to the CS - was present on trial $5, F(1,84)=42.22, p<.001, \eta_{\mathrm{p}}^{2}=.34$, with no differences across conditions, $F<1$.

The differentiation was still present in the first block of the extinction phase, $F(1,84)=30.64, p<.001, \eta_{\mathrm{p}}^{2}=.27$, with no differences across conditions, $F<1$. Overall, differential desires decreased during extinction $(\mathrm{CS} \times \mathrm{B}), F(2.56,215.33)=3.12, p=.03$, $\eta_{\mathrm{p}}^{2}=.04$, and this extinction interacted with condition $(\mathrm{CS} \times \mathrm{B} \times \mathrm{C})$, $F(5.13,215.33)=2.61, p=.03, \eta_{\mathrm{p}}^{2}=.06$ (see Fig. 2). Next, extinction across each pair of conditions was examined. Conditioned desires extinguished similarly in the control vs. UNP condition, $F<1$, but both differed from the OR condition, $F(2.51,140.42)=4.83, p=.005$, $\eta_{\mathrm{p}}^{2}=.08 ; F(2.71,152.02)=2.77, p=.05, \eta_{\mathrm{p}}^{2}=.05$. To further examine these significant differences, analyses were conducted on differentiations between the $\mathrm{CS}+$ and $\mathrm{CS}$ - scores on each block using a Bonferroni-corrected alpha of .0125 . On the second extinction block, the differentiations in the control and UNP conditions were smaller than the differentiation in the OR condition, control vs. OR:
$F(1,56)=7.85, p=.007, \eta_{\mathrm{p}}^{2}=.12$; OR vs. UNP: $F(1,56)=7.23$, $p=.009, \eta_{\mathrm{p}}^{2}=.11$. On the subsequent blocks (3-5), differential desires appeared similar across these pairs of conditions, control vs. OR block 3-5: $F(1,56)=2.32, p=.13, \eta_{\mathrm{p}}^{2}=.04, F(1,56)=4.27$, $p=.044, \eta_{\mathrm{p}}^{2}=.07 ; F=1.62, n s$, OR vs. UNP block $3-5: F(1$, $56)=2.21, p=.14, \eta_{\mathrm{p}}^{2}=.04 ; F(1,56)=3.30, p=.08, \eta_{\mathrm{p}}^{2}=.06 ; F<1$. On block 5 , a differentiation between the $\mathrm{CS}+$ and $\mathrm{CS}-$ was still present, $F(1,84)=22.10, p<.001, \eta_{\mathrm{p}}^{2}=.21$, that was similar across conditions, $F<1$. Thus, overall, this pattern of results suggests a delayed extinction of conditioned desires when occasional reinforcements are given during extinction. The results further suggest that extinction of conditioned desires was successful to some extent, although it was not complete. Impulsivity did not moderate extinction performance $(\mathrm{CS} \times \mathrm{B} \times \mathrm{I} ; \mathrm{CS} \times \mathrm{B} \times \mathrm{C} \times \mathrm{I}), F s<1$.

On reacquisition trial 1 , no differentiation was present anymore, $F<1$, although there was a trend that the differentiation differed across conditions, $F(2,84)=2.56, p=.08, \eta_{\mathrm{p}}^{2}=.06$. Reacquisition was significant $(\mathrm{CS} \times \mathrm{T}), F(2.33,195.67)=45.11, p<.001, \eta_{\mathrm{p}}^{2}=.35$, with no differences across conditions, $(\mathrm{CS} \times \mathrm{T} \times \mathrm{C}), F=1.01$ (see Fig. 2). Impulsivity moderated the reacquisition of the desire for chocolate mousse $(\mathrm{CS} \times \mathrm{T} \times \mathrm{I}), F(2.33,195.67)=5.08, p=.005$,

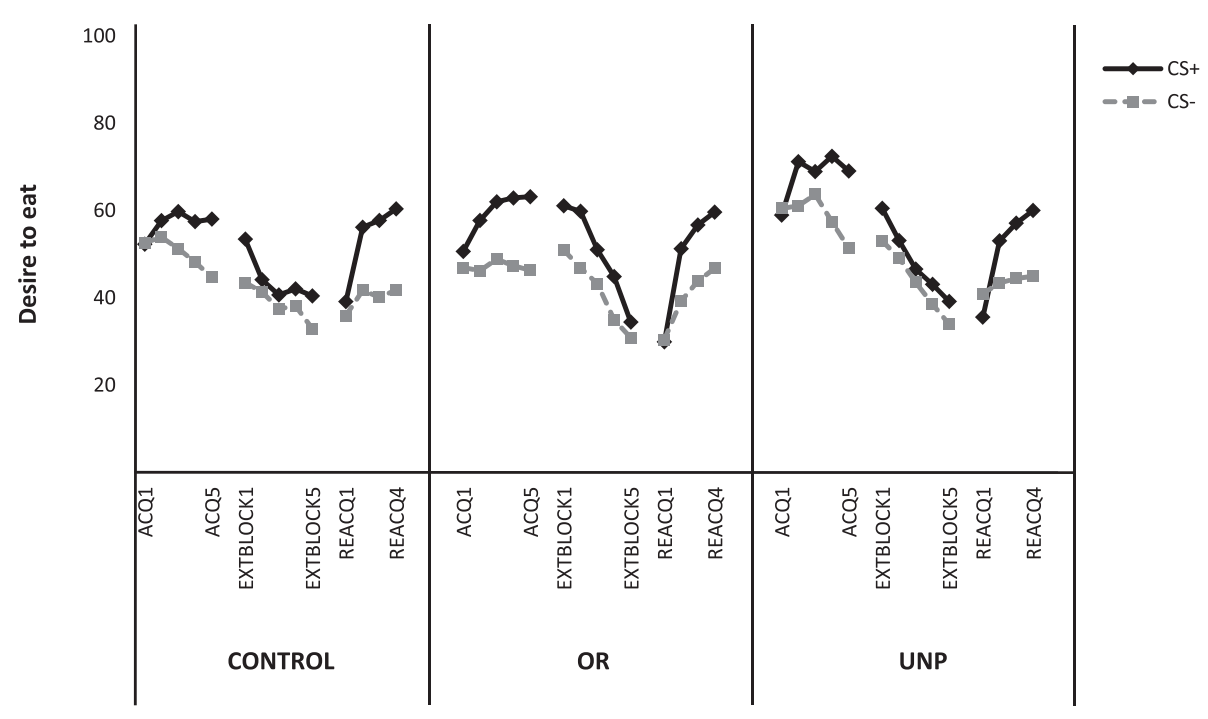

Fig. 2. Mean desire for chocolate mousse by CS-type, trial or block, condition, and phase of the experiment. 
$\eta_{\mathrm{p}}^{2}=.06$ : impulsivity was associated with a less pronounced reacquisition of conditioned desires, independent of condition $(\mathrm{CS} \times \mathrm{T} \times \mathrm{C} \times \mathrm{I}), F=1.40$, ns (see Fig. 3 ). On reacquisition trial 4, a significant differentiation between the CS + and CS- was present, $F(1,84)=60.11, p<.001, \eta_{\mathrm{p}}^{2}=.42$, with no differences across conditions, $F<1$. Higher impulsivity was associated with a smaller differentiation on this trial, $F(1,84)=5.91, p=.02, \eta_{\mathrm{p}}^{2}=.07$, independent of condition, $F=1.04$.

\subsection{Salivation}

Salivation data of one participant was missing. Salivation differed across measurements (baseline, $\mathrm{CS}+$ and $\mathrm{CS}-$ reacquisition), $F(2,166)=6.87, p=.001, \eta_{\mathrm{p}}^{2}=.08$, independent of condition, $F=1.21, n s$, impulsivity, $F<1$, and their interaction, $F=1.13, n s$. Salivation increased from baseline to $\mathrm{CS}+(p=.001)$ and from baseline to $\mathrm{CS}-(p=.02)$, but salivation was similar for the $\mathrm{CS}+$ and $\mathrm{CS}-(p=.27)$. Thus, no clear evidence was found for a conditioned salivary response [grams $\mathrm{M}$ (SD) control: baseline .36 (.30); CS + .51 (.31); CS - .50 (.30); OR: baseline .44 (.38); CS+ .48 (.32); CS- .43 (.34); UNP: baseline .39 (.24); CS+ .51 (.41); CS - .47 (.37)].

\subsection{CS preference}

The CS + was preferred over the CS - by 74 participants (82.2\%), $p<.001$. CS preference did not differ across conditions, $\chi^{2}(1$, $N=90)=.15, p=.93$.

\section{Discussion}

In this study, the effects of different extinction procedures on the extinction and reacquisition of appetitive responses to foodassociated cues were assessed. Additionally, it was examined whether impulsivity would affect conditioned responses. The results were partly in line with our hypotheses. Participants who received occasional reinforcements during extinction (OR condition) clearly showed a delayed extinction of US expectancies compared with participants who received normal extinction or unpaired presentations of the US during extinction (UNP condition). A comparable pattern was found for the desire to eat, although complete extinction of eating desires did not seem to be achieved in any of the conditions. Following the extinction procedures, participants received renewed CS-US pairings. In line with our hypotheses, a slower reacquisition of US expectancies was present in the OR and UNP conditions relative to the control condition. However, this pattern was not reflected in desire ratings: the conditions showed a similar reacquisition of conditioned desires to eat. Impulsivity did not moderate acquisition or extinction patterns, but was associated with a less pronounced reacquisition of the desire for chocolate mousse. Further, significant differences in salivation in response to the CS+ and CS- were not found. Finally, participants showed a clear conditioned preference for the $\mathrm{CS}+$ on a forced-choice task.

The finding that in humans, extinction of US expectancies and conditioned desires is slower when the CS has been occasionally reinforced by an appetitive US during extinction is new, and in line

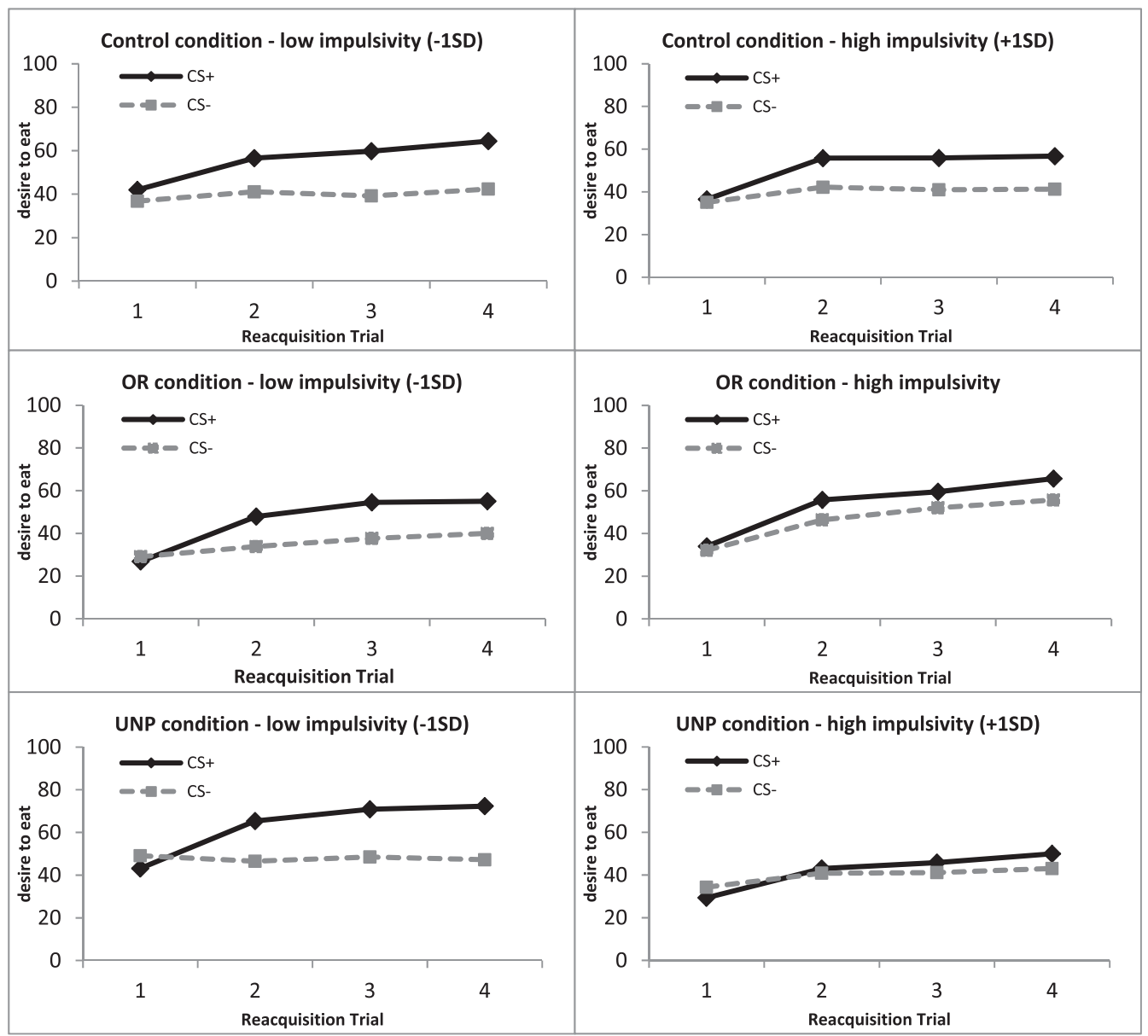

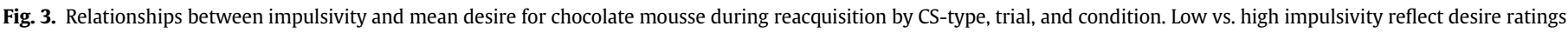
$1 \mathrm{SD}$ below vs. above the mean of the BIS- 11 . 
with experiments conducted in rats showing a slower loss of responding to the CS+ during extinction (Bouton et al., 2004). Note that this altered extinction is specific to reinforcement of the CS-US bond and not due to the mere fact that chocolate mousse was ingested during extinction, since extinction patterns in the UNP condition were mostly similar to those in the control condition. Another new finding is the slower reacquisition of US expectancies in the OR and UNP conditions relative to the control condition, which is also in line with rat studies (e.g., Bouton et al., 2004; Rauhut et al., 2001). Thus, it seems that, like rats, human participants may learn to associate a previously occasionally reinforced appetitive CS with a decreased chance of subsequent reinforcement of the CS. Presentation of unpaired USs during extinction seems similarly effective in reducing the magnitude of return of US expectancies that occurs during reacquisition, possibly because USs become associated with extinction, increasing generalization from extinction to reacquisition (see Bouton et al., 2004; Vervliet et al., 2010). Thus, judging from the present US expectancy data, occasional reinforcements and unpaired US presentations during extinction could be effective in reducing reacquisition in dieters who have achieved (some extent of) extinction of a food CS.

Although it is thought that US expectancies provide information about an important component of Pavlovian conditioning (Boddez et al., 2013; Mitchell, De Houwer, \& Lovibond, 2009), it has to be noted that the reacquisition pattern of conditioned desires did not support our hypothesis: reacquisition of conditioned desires was not slower for the OR and UNP conditions even though US expectancies showed this pattern. These apparently divergent findings are in line with findings of previous human appetitive conditioning studies. While US expectancies and desires often change in parallel during acquisition, extinction of conditioned desires seems to be more difficult to achieve than extinction of US expectancies (Papachristou et al., 2013; Van Gucht, Vansteenwegen, Beckers, \& Van den Bergh, 2008), and we previously reported similarly divergent response patterns during reacquisition (Van den Akker et al., 2014). This suggests the presence of different response systems that are differentially sensitive to different phases of conditioning (Papachristou et al., 2013; Van Gucht et al., 2008). With regard to eating desires, it has been noted that the difficulty to extinguish conditioned appetitive motivation resembles findings in evaluative conditioning studies: conditioned evaluations often do not show sensitivity to extinction (De Houwer, Thomas, \& Baeyens, 2001), and this seems to be the case as well for conditioned evaluations of food CSs (Papachristou et al., 2013; Van Gucht et al., 2008). In contrast, US expectancies have been proposed to reflect another response system related to preparatory reactions to food cues (Van Gucht et al., 2008). Another explanation for the response divergence might however be that in the present and previous experiments, extinction of US expectancies is often not complete either. Therefore, it cannot be ruled out that a small but significant differentiation in US expectancies that remains at the end of extinction causes the incomplete extinction of conditioned desires. Thus, it is possible that a complete extinction of expectancies would have resulted in an equally complete extinction of desires (but see Papachristou et al., 2013). Similarly, in case of reacquisition, it might be that the relatively slight reductions in returns of US expectancies during reacquisition were not sufficient to reduce the magnitude of reacquisition of conditioned desires. If US expectancies indeed need to be diminished more to achieve this, techniques that are able to further reduce a return of US expectancies during reacquisition might be crucial in diminishing this return of conditioned desires - for instance, more elaborate extinction techniques involving a greater number of occasional reinforcements and unpaired USs.
The present findings may have implications for increasing dieting success. Judging from the US expectancy data (i.e., a less rapid reacquisition in the OR and UNP conditions), the implication would be that dieters could, on the long-term, benefit from occasional lapses in their diet, if these lapses are followed by adherence to their diet (i.e., nonreinforced food cues). However, in our study, occasional reinforced extinction did not slow down the reacquisition of eating desires, while desires/cravings for food are thought to be important predictors for actual eating behavior and relapse (e.g., Rudak \& Thomas, 2009). Additionally, unsuccessful dieters seem to more frequently eat high-calorie or 'forbidden foods' during their diets (Wing \& Hill, 2001). This raises the question whether occasional lapsing can improve dieting success, and if so, whether perhaps the manner or extent of lapsing matters. It seems too early however to conclude from the present data that occasional snacking during a diet can increase dieting success. Another way for occasional reinforced extinction to increase dieting success might be by reducing overeating within one eating episode, for instance when individuals consider their diet "broken" after one bite of forbidden food and subsequently engage in disinhibited eating. Such overeating may be prevented if individuals learn to associate one small snack (the CS) with no further (over) eating (Bouton, 2011). Finally, the results also suggest it might be beneficial to provide USs unpaired from their CSs. One obvious issue with implementing unpaired procedures to reduce responding to CSs is that this seems only practically possible for food cues that do not entail the sight, smell, or taste of food, since these CSs are usually present when food is consumed. However, this does not mean unpaired procedures cannot be utilized. In fact, consuming (moderate amounts of) binge foods in non-binge situations has previously been recommended to more successfully break the exclusive bond between binge cues and binge eating (Jansen, 1998).

In this study, impulsivity did not seem to be related to a slower extinction of US expectancies. This finding is in contrast with two previous studies conducted in our lab in which a design was used very similar to the one in the present study (Van den Akker et al., 2014). Slight differences with the previous designs were present: as opposed to the previous studies, no salivation measurements were conducted during the procedure, and slightly shorter total trial times were used (approximately $3 \mathrm{~s}$ ). However, it is not clear how these alterations may counteract effects of impulsivity on extinction performance. Interestingly, impulsivity was associated with a reduced rate of reacquisition of conditioned desires to eat. This result is in contrast with a study reporting negative relationships between impulsivity and weight loss success (Nederkoorn et al., 2007), and with several addiction studies showing positive associations between impulsivity and risk of relapse (e.g., Doran, Spring, McChargue, Pergadia, \& Richmond, 2004; Yoon et al., 2007). However, we have previously found impulsivity to moderate reacquisition of conditioned desires in precisely the manner reported here (Van den Akker et al., 2014, study 2), and, in fact, some studies have associated higher impulsivity with lower relapse rates after treatment and greater benefits from a weight reduction program in overweight children (Papachristou, Nederkoorn, Giesen, \& Jansen, 2014; Pauli-Pott, Albayrak, Hebebrand, \& Pott, 2010). The authors suggested that their impulsive participants might have benefitted more from certain aspects of the behavior modification therapies that they had received, and one could speculate that the present extinction procedures have tapped into similar underlying constructs. Clearly, more research on the role of impulsivity in extinction and reacquisition of appetitive responses, and the relationship with clinical outcomes, is needed. Also, since only female students were included in the current study, it has yet to be examined whether the present findings would generalize to male and non-student populations. 
In sum, provision of occasional reinforcements and unpaired USs during extinction seem promising techniques to reduce reacquisition, although beneficial effects on reacquisition were not evident for the desire to eat. Future studies should aim to find out what exactly causes the divergent patterns of appetitive motivation and US expectancies and how these relate to dieting success. Weight loss methods may be improved by including trainings that successfully reduce reacquisition of appetitive responses, while, ideally, increasing the loss of responding during extinction.

\section{Acknowledgments}

This study is part of an ongoing project that is financed by the Netherlands Organisation for Scientific Research (NWO): Vici Grant 453.10.006, awarded to Anita Jansen.

The authors would like to thank Mark E. Bouton for his helpful comments on the design of this study.

\section{References}

Boddez, Y., Baeyens, F., Luyten, L., Vansteenwegen, D., Hermans, D., \& Beckers, T. (2013). Rating data are underrated: validity of US expectancy in human fear conditioning. Journal of Behavior Therapy and Experimental Psychiatry, 44(2), 201-206. http://dx.doi.org/10.1016/j.jbtep.2012.08.003.

Boutelle, K. N., Zucker, N. L., Peterson, C. B., Rydell, S. A., Cafri, G., \& Harnack, L. (2011). Two novel treatments to reduce overeating in overweight children: a randomized controlled trial. Journal of Consulting and Clinical Psychology, 79(6), 759-771. http://dx.doi.org/10.1037/a0025713.

Bouton, M. E. (2002). Context, ambiguity, and unlearning: sources of relapse after behavioral extinction. Biological Psychiatry, 52(10), 976-986. http://dx.doi.org/ 10.1016/s0006-3223(02)01546-9.

Bouton, M. E. (2011). Learning and the persistence of appetite: extinction and the motivation to eat and overeat. Physiology \& Behavior, 103(1), 51-58. http://dx. doi.org/10.1016/j.physbeh.2010.11.025.

Bouton, M. E., Woods, A. M., \& Pineño, O. (2004). Occasional reinforced trials during extinction can slow the rate of rapid reacquisition. Learning and Motivation, 35(4), 371-390. http://dx.doi.org/10.1016/j.lmot.2004.05.001.

Budak, A. R., \& Thomas, S. E. (2009). Food craving as a predictor of "Relapse" in the bariatric surgery population: a review with suggestions. Bariatric Nursing and Surgical Patient Care, 4(2), 115-121.

Corr, P. J. (2001). Testing problems in J. A. Gray's personality theory: a commentary on Matthews and Gilliland (1999). Personality and Individual Differences, 30(2), 333-352. http://dx.doi.org/10.1016/S0191-8869(00)00028-3.

Corr, P. J. (2002). Gray's reinforcement sensitivity theory and frustrative nonreward: a theoretical note on expectancies in reactions to rewarding stimuli. Personality and Individual Differences, 32, 1247-1253. http://dx.doi.org/10.1016/j.neubiorev 2004.01.005.

Corr, P. J., Pickering, A. D., \& Gray, J. A. (1995). Personality and reinforcement in associative and instrumental learning. Personality and Individual Differences, 19(1), 47-71. http://dx.doi.org/10.1016/0191-8869(95)00013-V.

Craske, M. G., Treanor, M., Conway, C. C., Zbozinek, T., \& Vervliet, B. (2014). Maximizing exposure therapy: an inhibitory learning approach. Behaviour Research and Therapy, 58(0), 10-23. http://dx.doi.org/10.1016/j.brat.2014.04.006.

Dawe, S., Gullo, M. J., \& Loxton, N. J. (2004). Reward drive and rash impulsiveness as dimensions of impulsivity: Implications for substance misuse. Addictive Behaviors, 29(7), 1389-1405. http://dx.doi.org/10.1016/j.addbeh.2004.06.004.

De Houwer, J., Thomas, S., \& Baeyens, F. (2001). Associative learning of likes and dislikes: a review of 25 years of research on human evaluative conditioning. Psychological Bulletin, 127(6), 853-869. http://dx.doi.org/10.1037/0033-2909. 127.6.853.

Doran, N., Spring, B., McChargue, D., Pergadia, M., \& Richmond, M. (2004). Impulsivity and smoking relapse. Nicotine \& Tobacco Research, 6(4), 641-647. http:/ dx.doi.org/10.1080/14622200410001727939.

Franken, I. H., van Strien, J. W., Nijs, I., \& Muris, P. (2008). Impulsivity is associated with behavioral decision-making deficits. Psychiatry Research, 158(2), 155-163. http://dx.doi.org/10.1016/j.psychres.2007.06.002.

Gorenstein, E. E., \& Newman, J. P. (1980). Disinhibitory psychopathology: a new perspective and a model for research. Psychological Review, 87, 301-315. http:/ dx.doi.org/10.1037/0033-295X.87.3.301.

Gorman, B. S., \& Allison, D. B. (1995). Measures of restrained eating. In D. B. Allison (Ed.), Handbook of assessment methods for eating behaviors and weight-related problems (pp. 149-184). Thousand Oaks, CA: Sage.

Guerrieri, R., Nederkoorn, C., \& Jansen, A. (2008). The effect of an impulsive personality on overeating and obesity: current state of affairs. Psychological Topics, 17, 265-286.

Havermans, R. C., \& Jansen, A. (2003). Increasing the efficacy of cue exposure treatment in preventing relapse of addictive behavior. Addictive Behaviors, 28(5), 989-994. http://dx.doi.org/10.1016/S0306-4603(01)00289-1.
Jansen, A. (1998). A learning model of binge eating: cue reactivity and cue exposure. Behaviour Research and Therapy, 36(3), 257-272. http://dx.doi.org/10.1016/ S0005-7967(98)00055-2.

Jansen, A., Broekmate, J., \& Heymans, M. (1992). Cue-exposure vs self-control in the treatment of binge eating: a pilot study. Behaviour Research and Therapy, 30(3), 235-241. http://dx.doi.org/10.1016/0005-7967(92)90069-S.

Jansen, A., Havermans, R., \& Nederkoorn, C. (2011). Cued overeating. In V. R. Preedy, R. R. Watson, \& C. R. Martin (Eds.), Handbook of behavior, food and nutrition (pp. 1431-1443). New York: Springer.

Jansen, A., Stegerman, S., Roefs, A., Nederkoorn, C., \& Havermans, R. (2010). Decreased salivation to food cues in formerly obese successful dieters. Psychotherapy and Psychosomatics, 79(4), 257-258. http://dx.doi.org/10.1159/ 000315131.

Laborda, M. A., McConnell, B. L., \& Miller, R. R. (2011). Behavioral techniques to reduce relapse after exposure therapy: applications of studies of experimental extinction. In T. R. Schachtmann, \& S. Reilly (Eds.), Associative learning and conditioning theory: Human and non-human applications (pp. 79-103). Oxford, UK: Oxford University Press.

MacKillop, J., \& Lisman, S. A. (2008). Effects of a context shift and multiple context extinction on reactivity to alcohol cues. Experimental and Clinical Psychopharmacology, 16(4), 322-331. http://dx.doi.org/10.1037/a0012686.

McDannald, M. A., Jones, J. L., Takahashi, Y. K., \& Schoenbaum, G. (2014). Learning theory. A driving force in understanding orbitofrontal function. Neurobiology of Learning and Memory, 108, 22-27. http://dx.doi.org/10.1016/j.nlm.2013.06.003.

Mitchell, C. J., De Houwer, J., \& Lovibond, P. F. (2009). The propositional nature of human associative learning. The Behavioral and Brain Sciences, 32(2), 183-198. discussion 198-246 http://dx.doi.org/10.1017/s0140525x09000855.

Nederkoorn, C., Braet, C., Van Eijs, Y., Tanghe, A., \& Jansen, A. (2006). Why obese children cannot resist food: the role of impulsivity. Eating Behaviors, 7(4), 315-322. http://dx.doi.org/10.1016/j.eatbeh.2005.11.005.

Nederkoorn, C., Jansen, E., Mulkens, S., \& Jansen, A. (2007). Impulsivity predicts treatment outcome in obese children. Behaviour Research and Therapy, 45(5), 1071-1075. http://dx.doi.org/10.1016/j.brat.2006.05.009.

Ogden, C. L., Carroll, M. D., Kit, B. K., \& Flegal, K. M. (2012). Prevalence of obesity in the United States, 2009-2010. NCHS Data Brief, 82, 1-8. http://dx.doi.org/10. 1111/j.1467-789X.2005.00165.x.

Papachristou, H., Nederkoorn, C., Beunen, S., \& Jansen, A. (2013). Dissection of appetitive conditioning. Does impulsivity play a role? Appetite, 69(0), 46-53. http://dx.doi.org/10.1016/j.appet.2013.05.011.

Papachristou, H., Nederkoorn, C., Giesen, J. C. A. H., \& Jansen, A. (2014). Cue reactivity during treatment, and not impulsivity, predicts an initial lapse after treatment in alcohol use disorders. Addictive Behaviors, 39(3), 737-739. http:// dx.doi.org/10.1016/j.addbeh.2013.11.027.

Patterson, C. M., \& Newman, J. P. (1993). Reflectivity and learning from aversive events: toward a psychological mechanism for the syndromes of disinhibition. Psychological Review, 100, 716-736. http://dx.doi.org/10.1037/0033-295X.100.4. 716.

Patton, J. H., Stanford, M. S., \& Barratt, E. S. (1995). Factor structure of the Barratt Impulsiveness Scale. Journal of Clinical Psychology, 51(6), 768-774. http:// dx.doi.org/10.1002/1097-4679(199511)51:63.0.CO;2-1.

Pauli-Pott, U., Albayrak, Ö., Hebebrand, J., \& Pott, W. (2010). Does inhibitory control capacity in overweight and obese children and adolescents predict success in a weight-reduction program? European Child \& Adolescent Psychiatry, 19(2), 135-141. http://dx.doi.org/10.1007/s00787-009-0049-0.

Polivy, J., Herman, C. P., \& Howard, K. (1988). The Restraint Scale: assessment of dieting. In M. Hersen, \& S. Bellack (Eds.), Dictionary of behavioural assessment techniques (pp. 377-380). New York: Pergamon.

Power, M. L., \& Schulkin, J. (2008). Anticipatory physiological regulation in feeding biology: cephalic phase responses. Appetite, 50(2-3), 194-206. http://dx.doi. org/10.1016/j.appet.2007.10.006.

Rauhut, A. S., Thomas, B. L., \& Ayres, J. J. B. (2001). Treatments that weaken Pavlovian conditioned fear and thwart its renewal in rats: Implications for treating human phobias. Journal of Experimental Psychology: Animal Behavior Processes, 27(2), 99-114. http://dx.doi.org/10.1037/0097-7403.27.2.99.

Stanford, M. S., Mathias, C. W., Dougherty, D. M., Lake, S. L., Anderson, N. E., \& Patton, J. H. (2009). Fifty years of the Barratt Impulsiveness Scale: an update and review. Personality and Individual Differences, 47(5), 385-395. http://dx.doi.org/ 10.1016/j.paid.2009.04.008.

Tetley, A. C., Brunstrom, J. M., \& Griffiths, P. L. (2010). The role of sensitivity to reward and impulsivity in food-cue reactivity. Eating Behaviors, 11(3), 138-143. http://dx.doi.org/10.1016/j.eatbeh.2009.12.004.

Van Gucht, D., Baeyens, F., Hermans, D., \& Beckers, T. (2013). The inertia of conditioned craving. Does context modulate the effect of counterconditioning? Appetite, 65(0), 51-57. http://dx.doi.org/10.1016/j.appet.2013.01.019.

Van Gucht, D., Baeyens, F., Vansteenwegen, D., Hermans, D., \& Beckers, T. (2010). Counterconditioning reduces cue-induced craving and actual cue-elicited consumption. Emotion, 10(5), 688-695. http://dx.doi.org/10.1037/a0019463.

Van Gucht, D., Vansteenwegen, D., Beckers, T., \& Van den Bergh, O. (2008). Return of experimentally induced chocolate craving after extinction in a different context: divergence between craving for and expecting to eat chocolate. Behaviour Research and Therapy, 46(3), 375-391. http://dx.doi.org/10.1016/j. brat.2008.01.003.

Van den Akker, K., Jansen, A., Frentz, F., \& Havermans, R. C. (2013). Impulsivity makes more susceptible to overeating after contextual appetitive conditioning. Appetite, 70, 73-80. http://dx.doi.org/10.1016/j.appet.2013.06.092. 
Van den Akker, K., Jansen, A., Havermans, R. C., \& Bouton, M. E. (2014). Diet today, indulge tomorrow: partial reinforcement of food cues and impulsivity slow down extinction. A new model of unsuccessful dieting. Appetite, 81, 242-252. http://dx.doi.org/10.1016/j.appet.2014.06.024.

Vervliet, B., Vansteenwegen, D., \& Hermans, D. (2010). Unpaired shocks during extinction weaken the contextual renewal of a conditioned discrimination. Learning and Motivation, 41(1), 22-31. http://dx.doi.org/10.1016/j.lmot.2009.08. 001.

Weiss, E. C., Galuska, D. A., Khan, L. K., \& Serdula, M. K. (2006). Weight-control practices among U.S. adults, 2001-2002. American Journal of Preventive Medicine, 31(1), 18-24. http://dx.doi.org/10.1016/j.amepre.2006.03.016.

Wing, R. R., \& Hill, J. O. (2001). Successful weight loss maintenance. Annual Review of Nutrition, 21, 323-341. http://dx.doi.org/10.1146/annurev.nutr.21.1.323.
Wing, R. R., \& Phelan, S. (2005). Long-term weight loss maintenance. American Journal of Clinical Nutrition, 82(1), 222S-225S.

Woods, A. M., \& Bouton, M. E. (2007). Occasional reinforced responses during extinction can slow the rate of reacquisition of an operant response. Learning and Motivation, 28, 56-74. http://dx.doi.org/http://dx.doi.org/10.1016/j.lmot. 2006.07.003.

Yoon, J. H., Higgins, S. T., Heil, S. H., Sugarbaker, R. J., Thomas, C. S., \& Badger, G. J. (2007). Delay discounting predicts postpartum relapse to cigarette smoking among pregnant women. Experimental and Clinical Psychopharmacology, 15(2), 176-186. http://dx.doi.org/10.1037/1064-1297.15.2.186.

Zinbarg, R. E., \& Mohlman, J. (1998). Individual differences in the acquisition of affectively valenced associations. Journal of Personality and Social Psychology, 74, 1024-1040. http://dx.doi.org/10.1037/0022-3514.74.4.1024. 